\title{
Bronchoscopic Targeted Lung Denervation in Patients with Severe Asthma: Preliminary Findings
}

\author{
Jorine E. Hartman ${ }^{\mathrm{a}, \mathrm{b}}$ Karthi Srikanthan ${ }^{\mathrm{c}, \mathrm{d}, \mathrm{e}}$ Cielito Caneja ${ }^{\mathrm{c}, \mathrm{e}}$ \\ Nick H.T. ten Hacken ${ }^{a, b}$ Huib A.M. Kerstjens ${ }^{a, b}$ Pallav L. Shah ${ }^{c, d, e}$ \\ Dirk-Jan Slebos ${ }^{a, b}$
}

aDepartment of Pulmonary Diseases, University of Groningen, University Medical Centre Groningen, Groningen, The Netherlands; ${ }^{b}$ Groningen Research Institute for Asthma and COPD, University of Groningen, University Medical Centre Groningen, Groningen, The Netherlands; ' $R o y a l$ Brompton Hospital, London, UK;

${ }^{\mathrm{d}}$ National Heart \& Lung Institute, Imperial College, London, UK; ${ }^{e}$ Chelsea \& Westminster Hospital, London, UK

\section{Established Facts}

- A small proportion of the total asthma population has severe asthma, but it accounts for a large proportion of the asthma costs.

- The current treatment options for severe asthma are not sufficient for all patients, and new treatment options are needed.

- Targeted lung denervation is an experimental treatment that uses radiofrequency energy to disrupt peribronchial vagal innervation in the lungs and was thus far only investigated in patients with COPD.

\section{Novel Insights}

- Two first severe asthma patients treated with TLD tolerated the procedure well, and no unexpected (serious) adverse events occurred up to 1 year after treatment.

- The combination of both the need for additional severe asthma treatment options and targeting a known underlying pathophysiological mechanism makes TLD a hypothetical future therapy for this patient group.

- Further investigation of the TLD treatment in severe asthma patients would be useful.

\section{Keywords}

Acetylcholine · Asthma - Bronchoscopy · Targeted lung denervation - Vagal nerve

Jorine E. Hartman and Karthi Srikanthan contributed equally.

\section{Abstract}

Treatment options for severe asthma are limited, particularly in those patients who do not meet criteria for biologicals. Targeted lung denervation (TLD) is the bronchoscopic ablation of the peribronchial vagal nerve trunks to reduce cholinergic stimulation of airway smooth muscle and submuco-
(C) 2021 The Author(s)

Published by S. Karger AG, Basel

This is an Open Access article licensed under the Creative Commons Attribution-NonCommercial-4.0 International License (CC BY-NC) (http://www.karger.com/Services/OpenAccessLicense), applicable to the online version of the article only. Usage and distribution for commercial purposes requires written permission.
Correspondence to:

Jorine E. Hartman, j.hartman@umcg.nl 
sal glands. This report describes the experience of the first 2 asthma patients treated with TLD worldwide. The participants were 54 and 51 years of age, and both had severe asthma (GINA 5) ( $\mathrm{FEV}_{1}: 53 \%$ and $113 \%$ of predicted; AQLQ scores: 5.3 and 4.4). Both participants were treated with TLD in a single day-case procedure under general anaesthesia. Lung function, health status, and adverse event data were collected at baseline and 12 months after TLD. No treatment-related serious adverse events were reported up to 12 months. Cough symptoms improved in both participants, and 1 participant reported a marked reduction in rescue medication use at 6 months. There were no significant changes in spirometry, lung volumes, or health status. In conclusion, TLD was performed safely in both participants, but more evidence is needed to clarify safety and efficacy of TLD in severe asthma. Therefore, further investigation of the treatment in severe asthma patients would be useful.

\footnotetext{
(C) 2021 The Author(s)

Published by S. Karger AG, Basel
}

\section{Introduction}

Approximately $3-10 \%$ of the asthma population has severe asthma [1], but it accounts for an estimated $60 \%$ of the total asthma costs [2]. For this patient group, the available additional treatments are biologicals or bronchial thermoplasty (BT) [1]. The use of biologicals is not only expensive but also limited to allergic and/or eosinophilic phenotypes. BT is not available in many countries and has the disadvantage that it requires 3 separate bronchoscopic procedures. Therefore, there is a need and op- portunity for additional treatment options for this severe patient group, especially for the non-eosinophilic phenotypes.

Targeted lung denervation (TLD) is a novel bronchoscopic treatment, currently under investigation in clinical trials for COPD patients (NCT03639051) [3-6]. The TLD mechanism of action is disruption of the peribronchial vagal innervation of the airways by radiofrequency energy, thereby decreasing the release of acetylcholine (Fig. 1). Patients with severe asthma have an increased cholinergic tone, which causes bronchoconstriction and hyperresponsive airways, and anticholinergic drug treatments have been shown to be of benefit [7-9]. TLD could therefore also be beneficial for patients with severe uncontrolled asthma. In this report, we describe the results of the very first 2 asthma patients who underwent this innovative bronchoscopic treatment.

\section{Case Reports}

Both patients were treated in the RELIEF-1 trial(NCT02872298) and followed until at least 1 year after treatment. A complete list of in- and exclusion criteria can be found in the NCT clinical trial record. The study was approved by the ethics committees of both participating hospitals and terminated early because of logistical reasons (sponsor decision due to difficulty with recruiting, and yet no restart due to COVID). Both patients provided written informed consent. The 2 included patients were a 54-year-old male and a 51-year-old female, both GINA 5, pre-bronchodilator $\mathrm{FEV}_{1}$ $53 \%$ and $113 \%$ of predicted, AQLQ overall score 5.3 and 4.4 , and no history of smoking (see Table 1 for more detailed patient characteristics).
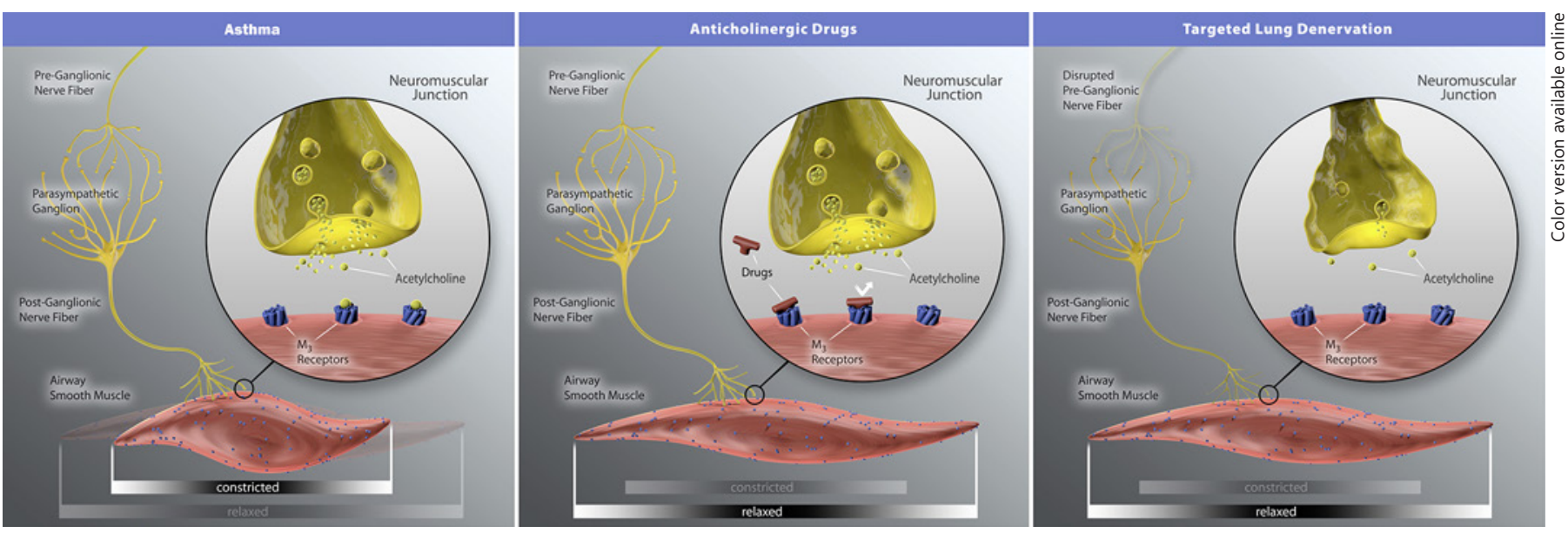

Fig. 1. Schematic overview of the proposed mechanism of action of the targeted lung denervation treatment in comparison with anticholinergic drugs. The figure was obtained with approval to use by Nuvaira Inc. (Minneapolis, MN, USA).

Bronchoscopic Targeted Lung Denervation in Severe Asthma
Respiration 2022;101:184-189 DOI: $10.1159 / 000518515$ 
Table 1. Patient characteristics at baseline and at 3- through 12-month FU after treatment

\begin{tabular}{lll}
\hline & Subject 1 & Subject 2 \\
\hline Gender & Male & Female \\
Age, years & 54 & 51 \\
Age at asthma onset, years & $30-39$ & $40-50$ \\
GINA step & 5 & 5 \\
Asthma triggers & Exercise, infections, weather & Exercise, infections, irritants, weather \\
Asthma medication use & Fluticasone/formoterol $(500 / 20 \mu g) 2 \times \mathrm{d} 1, \quad$ & Tiotropium $(5 \mu \mathrm{g}) 1 \times \mathrm{d} 1$, beclometasone/ \\
& tiotropium $(18 \mu \mathrm{g}) 1 \times \mathrm{d} 1, \mathrm{salbutamol}(200 \mu \mathrm{g})$ & formoterol $(200 \mu \mathrm{g} / 6 \mu \mathrm{g}) 2 \times \mathrm{d} 2$, prednisolone \\
& PRN, montelukast $(10 \mathrm{mg}) 1 \times \mathrm{d} 1 \mathrm{mg}) 1 \times \mathrm{d} 1$ & \\
History of smoking? & & No \\
Symptoms days during 4-week run-in, total $n$ & 2 & 15 \\
Asthma-related hospitalizations $<12 \mathrm{months}, n$ & 0 & 0
\end{tabular}

\begin{tabular}{|c|c|c|c|c|c|c|c|c|}
\hline Rescue medication, average puff/day & 0.4 & 0.4 & nd & nd & $1.6^{9}$ & $0.1^{9}$ & 0 & 0 \\
\hline Rescue medication use, average days, $n$ & 1.5 & 1 & nd & nd & $4.5^{9}$ & $0.5^{9}$ & 0 & 0 \\
\hline $\mathrm{FEV}_{1}$ pre-bronchodilator, \%pred & 53 & 48 & 54 & nd* & 113 & 122 & 114 & 115 \\
\hline $\mathrm{FEV}_{1}$ post-bronchodilator, \%pred & 57 & 58 & 69 & nd* & 119 & 118 & 117 & 112 \\
\hline $\mathrm{PC} 20, \mathrm{mg} / \mathrm{mL}$ & 16.0 & na & nd & nd* & 0.6 & na & 0.7 & 0.5 \\
\hline AQLQ score & 5.3 & 6.2 & 6.3 & 6.3 & 4.4 & 5.0 & 5.8 & 6.0 \\
\hline LCQ, total score & 9.3 & 17.2 & 18.0 & 18.2 & 11.0 & 14.0 & 18.2 & 19.5 \\
\hline
\end{tabular}

GINA, Global Initiative for Asthma; $n$, number; FU, follow-up; nd, not done; FEV 1 , forced expiratory volume in $1 \mathrm{~s}$; \%pred, percentage of predicted; $\mathrm{PC} 20$, the provocative concentration of methacholine that results in a $20 \%$ drop in $\mathrm{FEV}_{1}$; ACQ, asthma control questionnaire (including 7 questions); AQLQ, asthma quality of life questionnaire; LCQ, Leicester Cough Questionnaire; na, not applicable, test not part of study visit. 'Subject 2 used beclometasone/ formoterol as rescue medication and increased the frequency when needed. $\wedge$ Number of asthma-related hospitalizations in the 12 months prior to enrolment. *Not done due to COVID-19.

The TLD treatment was performed using the Nuvaira ${ }^{\mathrm{TM}}$ Lung Denervation system in the distal left and proximal right main bronchi (Nuvaira, Minneapolis, MN, USA) (Fig. 2) as previously described [4]. In both subjects, the TLD procedure was performed as a single outpatient bronchoscopic procedure under general anaesthesia (lasting 60 and $100 \mathrm{~min}$, with 2.4 and 5.5 min of fluoroscopy). Full circumferential treatment of both main bronchi was completed in subject 1 . However, 2 right-sided quadrants (medial and posterior) were not treated in subject 2 to prevent inadvertent ablation injury to the oesophagus, which was deemed too close to the right main bronchus. In both subjects, there were no procedural complications. Up to 12 months after treatment, no treatment-related serious adverse events (AE) were reported. One probable related $\mathrm{AE}$ occurred (cough, directly after the procedure, requiring no treatment) and one possible related $\mathrm{AE}$ (cough, 6 days after the procedure, medication use and unscheduled physician visit).

No differences were noted in spirometry, body plethysmography, or quality of life outcomes during study follow-up (FU) (see Table 1). Cough symptoms measured using the Leicester Cough Questionnaire improved in both patients at 1-year FU (subject 1: 9.3-18.2 and subject 2: 11.0-19.5). One patient had a reduction in number of days with the need to use rescue medication ( 4.5 to 0.5 days/week) and the average rescue medication puffs per day (1.6 to $0.1 /$ day) 3 months after treatment, but the other patient did not (1.5-1 day/week and 0.4 puffs/day at baseline and unchanged at 3-month FU). The same patient also had an improvement in asthma control measured by the asthma control questionnaire (ACQ) (2.6-1.1 at 6-month FU) while in the other patient, the ACQ score did not change (1.6-1.4 at 6-month FU).

\section{Discussion/Conclusion}

Of course, with only the results of the first 2 asthma patients treated with TLD, we cannot draw any conclusions yet regarding safety or efficacy of the treatment for this patient group. However, in both patients, the procedure was feasible and safe, with both subjects tolerating the procedure well, and no unexpected AE occurred up to 1 year after treatment.

Disrupting vagal innervation in the lungs by targeting the nerves in asthma patients is not a novel idea. The first attempts were performed surgically, which already started in the 1920s when according to an ancient review, al- 


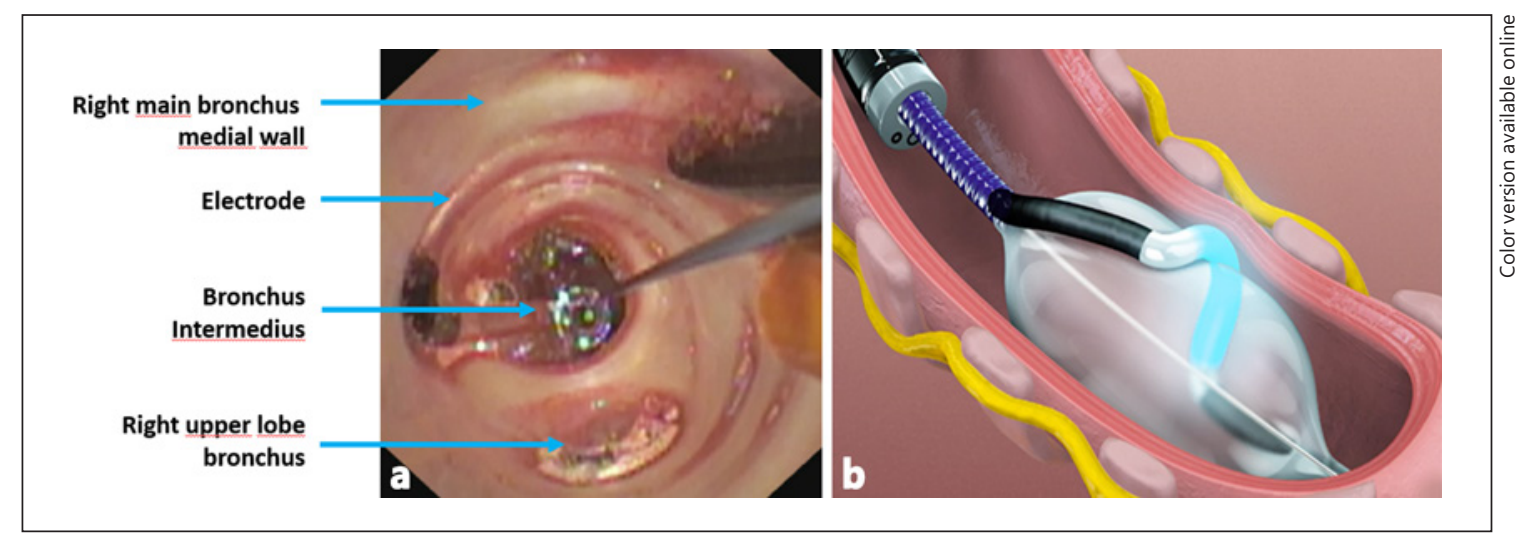

Fig. 2. Overview of the components of the Nuvaira ${ }^{\mathrm{TM}}$ lung denervation system. a Bronchoscopic view through the balloon catheter with a visible radiofrequency electrode in the right main bronchus. b Graphical representation of the activated radiofrequency catheter in the left main bronchus, with in yellow the relative position of the airway nerves. The figure was obtained with approval to use by Nuvaira Inc. (Minneapolis, MN, USA).

ready $>200$ (!) surgeries were performed [10]. Later on, positive effects were reported on an improvement in the frequency and severity of asthmatic attacks [11] and according to the authors on allergic and infectious processes of the lung [12]. However, afterwards (accessible) published studies waned, and the surgical resection of lung airway nerve trunks has not been practiced, probably due to a high risk of procedure-related mortality and side effects like gastric denervation events. Therefore, in the past decade, the less-invasive and more targeted bronchoscopic alternative was developed [3]. A first study using TLD in animals showed that airway resistance was reduced [13]. TLD has thus far only been investigated in COPD patients, with the results of 123 treated patients being published in 4 different trials [3-6]. Recently, also the surgical approach was revived by performing a unilateral resection of the internal branch of the superior laryngeal nerve in 41 asthma patients with frequent asthma attacks and comparing with a non-randomized control group, reporting an uneventful postoperative period and a decrease in asthma attacks [14]. A bronchoscopic treatment would be preferable because it is less invasive and could be more targeted to the pulmonary nerves.

The mechanism of action of TLD is comparable to pharmacologic nerve blockade using an LAMA, such as tiotropium. In COPD, LAMA therapy is already an established treatment option and has shown to improve symptoms and health status as well as reduce exacerbations and related hospitalizations [15]. The first randomized shamcontrolled trial results of TLD in patients with COPD showed a reduction in exacerbations requiring hospitalizations and that the treatment has an acceptable safety profile [4]. Known complications are a bronchoscopicinduced COPD exacerbation and gastrointestinal symptoms in the post-procedural period [4]. LAMA as a potential add-on asthma treatment, especially for severe asthma patients, has gained interest in the past decade, showing benefits in reducing the need for rescue oral steroids and exacerbation risk [16-18]. With a similar mechanism of action and the results in COPD patients so far, TLD could also have potential in severe asthma patients. A bronchoscopic treatment could be more challenging in asthma patients due to more reactive airways, but no procedural problems occurred in our first 2 patients who underwent TLD. TLD could have the advantage over pharmacologic treatments that it targets the nerve directly, but still it is questionable whether all nerve branches can be reached and what the sustainability of the treatment is, with regard to, for example, nerve regeneration. Recently, an animal study with efferent neuron staining showed absence of regeneration up to 640 days after TLD treatment [19]. Interestingly, the bronchodilator response to LAMA was maintained after TLD in COPD patients, and therefore TLD could be considered an add-on treatment instead of replacement of LAMA therapy [20].

According to the most recent GINA guidelines, there is a need for adjuvant treatment options for the management of severe asthma [1]. One of these is bronchoscopic BT. BT also uses radiofrequency energy; however, in contrast to TLD, the energy is delivered locally to the airway wall targeting all accessible airways which are $2 \mathrm{~mm}$ or larger [21]. The proposed BT mechanism of action is reduction in airway smooth muscle mass by intervening in airway remodelling and modulating the composition of 
the extracellular matrix [21]. The strongest evidence is a positive effect on the exacerbation rate after treatment, while effects on lung function or asthma control are modest or lacking $[1,22,23]$. The comparison between TLD and BT is interesting as both are bronchoscopic treatments which use radiofrequency energy. However, both treatments have the same goals but use the radiofrequency differently (localization and depth of energy) and have a different proposed mechanism of action (smooth muscle mass reduction vs. anticholinergic action). On the other hand, for both, the main benefit seems to be a decrease in exacerbation rate (for TLD only shown in COPD patients). The potential advantages of TLD over BT are that theoretically the effect of treatment reaches smaller airways, is likely to cause less airway inflammation due to radiofrequency energy, and can be completed in one sitting.

Biologicals are indicated specifically for allergic and/or eosinophilic phenotypes [1]. Whether there is a specific phenotype which benefits most from TLD is currently unknown. An analysis in a small subgroup of 7 COPD patients showed an inhibition of inflammation after TLD (e.g., decrease in neutrophils, IL-8, and mucin MUC5AC) [24]. Acetylcholine not only induces bronchoconstriction and mucus secretion but also regulates airway inflammation and remodelling [25]. Reduction in neuronal acetylcholine could therefore be postulated to improve inflammation, an effect shown in animals and on cells but not in humans so far [25]. However, it needs to be further investigated whether there is a specific phenotype for TLD, both in asthma and COPD.

To conclude, we presented the first 2 patients with severe asthma who underwent the experimental bronchoscopic TLD treatment. Both patients tolerated the treatment well, and no safety issues occurred. The combination of both the need for additional severe asthma treatment options and targeting a known underlying pathophysiological mechanism makes TLD a hypotheti- cal future therapy for this patient group. Therefore, further investigation of the treatment in severe asthma patients would be useful.

\section{Statement of Ethics}

The RELIEF-1 trial was submitted to the ethics committees of both participating hospitals, and both patients provided informed consent.

\section{Conflict of Interest Statement}

J.H., K.S., C.C., and H.K. have nothing to disclose. N.H., P.S., and D.S. were the principal investigators of the RELIEF-1 trial. D.S. is a physician advisor to Nuvaira Inc., Minneapolis, MN, USA.

\section{Funding Sources}

The RELIEF-1 trial was funded by Nuvaira Inc., Minneapolis, MN, USA. The funding source had no involvement in writing this manuscript. All authors participated as investigators or study coordinators in the trial, and the departments received funding for the execution of the trial.

\section{Author Contributions}

All authors participated as investigators or study coordinators in the trial and were involved in data collection. J.E.H. and D.J.S. wrote the first draft of the manuscript and made revisions after feedback from co-authors. All the authors meet the definition of an author as stated by the International Committee of Medical Journal Editors, and all have seen and approved the final manuscript.

\section{Data Availability Statement}

All data generated or analysed during this study are included in this article. Further enquiries can be directed to the corresponding author.

\section{References}

1 (GINA) Global Initiative for Asthma. Global Strategy for Asthma Management and Prevention [Internet]; 2020 [cited 2020 Sep 17]. Available from: www.ginasthma.org.

2 Sadatsafavi M, Lynd L, Marra C, Carleton B, Tan WC, Sullivan S, et al. Direct health care costs associated with asthma in British Columbia. Can Respir J. 2010;17(2):74-80.

3 Slebos DJ, Klooster K, Koegelenberg CF, Theron J, Styen D, Valipour A, et al. Targeted lung denervation for moderate to severe COPD: a pilot study. Thorax. 2015;70(5): 411-9.

4 Slebos D-J, Shah PL, Herth FJ, Pison C, Schumann C, Hübner R-H, et al. Safety and adverse events after targeted lung denervation for symptomatic moderate to severe COPD (AIRFLOW): a multicenter randomized controlled trial. Am J Respir Crit Care Med. 2019; 200(12):1477-86.
5 Valipour A, Asadi S, Pison C, Jondot M, Kessler R, Benneddif K, et al. Long-term safety of bilateral targeted lung denervation in patients with COPD. Int J Chron Obstruct Pulmon Dis. 2018 Jul;13:2163-72.

6 Valipour A, Shah PL, Pison C, Ninane V, Janssens W, Perez T, et al. Safety and dose study of targeted lung denervation in moderate/severe COPD patients. Respiration. 2019; 98(4):329-39. 
7 Liccardi G, Salzillo A, Calzetta L, Cazzola M, Matera MG, Rogliani P. Can bronchial asthma with an highly prevalent airway (and systemic) vagal tone be considered an independent asthma phenotype? Possible role of anticholinergics. Respir Med. 2016;117:150-3.

8 Kerstjens HA, Disse B, Schröder-Babo W, Bantje TA, Gahlemann M, Sigmund R, et al. Tiotropium improves lung function in patients with severe uncontrolled asthma: a randomized controlled trial. J Allergy Clin Immunol. 2011;128(2):308-14.

9 Kerstjens HA, Engel M, Dahl R, Paggiaro P, Beck E, Vandewalker M, et al. Tiotropium in asthma poorly controlled with standard combination therapy. N Engl J Med. 2012;367(13): 1198-207.

10 Phillips EW, Scott W. The surgical treatment of bronchial asthma. Arch Surg. 1929;19(6): 1425-56.

11 Rienhoff WF, Gay L. Treatment of intractable bronchial asthma by bilateral resection of the posterior pulmonary plexus. Arch Surg. 1938; 37(3):456-69.

12 Dimitrov-Szokodi D, Husveti A, Balogh G. Lung denervation in the therapy of intractable bronchial asthma. J Thorac Surg. 1957;33(2): $166-84$.

13 Hummel JP, Mayse ML, Dimmer S, Johnson PJ. Physiologic and histopathologic effects of targeted lung denervation in an animal model. J Appl Physiol (1985). 2019 Jan;126(1):6776.
14 Kurbon U, Dodariyon H, Davlatov A, Janobilova S, Therwath A, Mirshahi M. Surgical treatment of bronchial asthma by resection of the laryngeal nerve. BMC Surg. 2015;15(109): 109.

15 Karner C, Chong J, Poole P. Tiotropium versus placebo for chronic obstructive pulmonary disease. Cochrane Database Syst Rev. 2014;7(7):CD009285.

16 FitzGerald JM, Hamelmann E, Kerstjens HAM, Buhl R. Asthma exacerbations and worsenings in patients aged 1-75 years with add-on tiotropium treatment. Prim Care Respir Med. 2020;30(38).

17 Kew KM, Dahri K. Long-acting muscarinic antagonists (LAMA) added to combination long-acting beta2-agonists and inhaled corticosteroids (LABA/ICS) versus LABA/ICS for adults with asthma. Cochrane Database Syst Rev. 2016;21(1):CD011721.

18 Sobieraj DM, Baker WL, Nguyen E, Weeda ER, Coleman CI, White CM, et al. Association of inhaled corticosteroids and long-acting muscarinic antagonists with asthma control in patients with uncontrolled, persistent asthma: a systematic review and meta-analysis. JAMA. 2018;319(14):1473-84.

19 Mayse ML, Norman HS, Peterson AD, Rouw KT, Johnson PJ. Targeted lung denervation in sheep: durability of denervation and longterm histologic effects on bronchial wall and peribronchial structures. Respir Res. 2020; 21(117):117.
20 Koegelenberg CF, Theron J, Slebos DJ, Klooster K, Mayse M, Gosens R. Antimuscarinic bronchodilator response retained after bronchoscopic vagal denervation in chronic obstructive pulmonary disease patients. Respiration. 2016;92(1):58-60.

21 Bonta PI, Chanez P, Annema JT, Shah PL, Niven R. Bronchial thermoplasty in severe asthma: best practice recommendations from an expert panel. Respiration. 2018;95:289300.

22 Wechsler ME, Laviolette M, Rubin AS, Fiterman J, Lapa e Silva JR, Shah PL, et al. Bronchial thermoplasty: long-term safety and effectiveness in patients with severe persistent asthma. J Allergy Clin Immunol. 2013;132(6): 1295-302.

23 Castro M, Rubin AS, Laviolette M, Fiterman J, De Andrade Lima M, Shah PL, et al. Effectiveness and safety of bronchial thermoplasty in the treatment of severe asthma: a multicenter, randomized, double-blind, shamcontrolled clinical trial. Am J Respir Crit Care Med. 2010;181(2):116-24.

24 Kistemaker LE, Slebos DJ, Meurs H, Kerstjens HA, Gosens R. Anti-inflammatory effects of targeted lung denervation in patients with COPD. Eur Respir J. 2015 Nov;46(5):148992.

25 Kistemaker LE, Gosens R. Acetylcholine beyond bronchoconstriction: roles in inflammation and remodeling. Trends Pharmacol Sci. 2015;36(3):164-71. 